\title{
O tempo e o espaço na vida cotidiana: reflexões a partir do filme 0 terminal
}

\section{Luciana Buksztejn Gomes}

Doutoranda e mestre em Comunicação Social pelo Programa de Pós-Graduação em Comunicação Social (PPGCOM) da Pontifícia Universidade Católica do Rio Grande do Sul (PUC-RS). Graduada em Direito pela PUC-RS.

E-mail: lucianabg.adv@gmail.com

\section{Daniela Firmino Cidade}

Mestranda pelo PPGCOM da PUC-RS.

Especialista em Comunicação com o Mercado pela Escola Superior de Propaganda e Marketing (ESPM). Especialização em Marketing pela Instituição Educacional São Judas Tadeu (IESJT). Graduada em Jornalismo pela Universidade Federal do Rio Grande do Sul (UFRGS).

E-mail: dfcidade@gmail.com
Resumo: Neste artigo, nos propomos a realizar uma releitura do filme $O$ terminal (The terminal, Steven Spielberg, 2004), destacando pontos que o aproximam às discussões acerca do tempo, espaço, lugar e não-lugar, por meio das lentes de alguns autores. Vemos o filme a partir da concepção de forasteiro, isto é, daquele que é estrangeiro em um determinado tempo e espaço. Com isso, buscamos trazer à tona aspectos que nos proporcionem pensar o cotidiano a partir dessas dimensões.

Palavras-chave: Tempo; Espaço; Lugar; Vida cotidiana; Forasteiro.

\section{Time and space in everyday life: reflections from the movie The terminal}

Abstract: In this article, we propose a re-reading of the film The Terminal (Steven Spielberg, 2004), highlighting points that approximate it to discussions about time, space, place and non-place, through the perspectives of some authors. We see the film based on the concept of the outsider (Schutz, 2003), the one who is a foreigner in a certain time and space. With this, we seek to bring up aspects that allow us to think about everyday life within these dimensions.

Keywords: Time; Space; Place; Everyday life; Outsider. 


\section{Considerações iniciais}

Observamos uma pluralidade de discussões em relação à forma como a humanidade tem conduzido sua vida cotidiana. Analisados por diferentes autores - recebendo distintas denominações como pós-modernidade (SANTOS, 2008) ou supermodernidade (AUGÉ, 1994) -, o tempo e o espaço parecem ser eleitos como preocupações atuais, assim como as ideias de lugar e não-lugar.

O que se percebe são certas alterações na forma como o homem vem incorporando essas dimensões e, a partir delas, conduzindo sua vida cotidiana. Segundo Santos (2008: 37), "é pelo lugar que revemos o Mundo e ajustamos nossa interpretação". Diante dessa afirmativa, propomos a reflexão sobre o filme $O$ terminal (The terminal, Steven Spielberg, 2004) a partir de três autores, de diferentes nacionalidades e formações e cujas obras permearam a temática, em nosso ver, de forma instigante e profunda.

${ }^{1} \mathrm{O}$ filme foi visto dublado em português e, até o momento de escrita deste artigo, encontra-se disponível no serviço de streaming Netflix. A produção é inspirada na história real do refugiado iraniano Merhan Karimi Nasseri, que ficou preso no aeroporto Charles de Gaulle, em Paris, vivendo no local por 18 anos (LOPES, 2010; FRANCE PRESSE, 2004).

\section{O terminal: ${ }^{1}$ enfoques para reflexão}

A proposta é apresentar a narrativa fílmica, destacando pontos que servem como "marcos" e auxiliam na identificação de aspectos trazidos pelos autores ora selecionados. Dessa forma, compreendemos $O$ terminal como uma possibilidade de reflexão que dialoga com as noções de tempo, espaço, lugar, vida cotidiana e forasteiro.

A história de Viktor Navorski, personagem interpretado por Tom Hanks, retrata a situação de um viajante que chega aos Estados Unidos, mas é impedido de sair do aeroporto. Isso porque, enquanto o voo estava em trânsito, houve em seu país de origem um golpe de Estado, o que gera suspensão dos passaportes e revogação do visto (cena aos 5'21"). Diante dessa situação, o diretor da alfândega explica ao protagonista: "até que isso seja resolvido, eu não tenho outra escolha a não ser deixar você ficar no terminal de trânsito internacional" (cena aos 8'20").

Sem entender bem o que está acontecendo, Viktor recebe vouchers de alimentação e um bipe e é conduzido por um policial até o terminal internacional. Ao chegar nesse ambiente, ele para e observa (cena aos 10'22"); percebe que estão passando imagens de seu país na televisão e se aproxima. Entende se tratar de uma crise, pelas imagens transmitidas e por algumas palavras que consegue compreender do inglês, língua que pouco domina. Sofre. Para novamente e observa aquele espaço no qual se encontra (cena aos 13'42"). A sensação que temos é que todos estão com pressa, uma multidão em movimento para as mesmas direções.

Chega a noite e o protagonista escolhe um local que está em obras para tentar descansar. Consegue improvisar algo que se assemelha a uma cama e faz do lugar o seu local de descanso a partir daquele momento. As cenas que seguem trazem alguns "marcos" que merecem nossa atenção. Viktor tenta achar emprego no terminal, mas parece não atender aos requisitos necessários, como ter endereço e telefone próprio. Com o passar dos dias, ele percebe que, se devolver os carrinhos espalhados pelo terminal e colocá-los enfileirados numa máquina, recebe moedas (passa a ter uma receita). Ele começa a fazer isso, o que lhe permite comprar comida - até que o diretor da alfândega percebe o movimento e cria um obstáculo para que o estrangeiro não consiga mais fazê-lo.

Viktor também percebe que precisa entender mais o idioma praticado naquele aeroporto. Assim, ele passa a ler a legenda das imagens da televisão, procurando identificar palavras-chave. Da mesma forma, compara palavras em inglês e na sua língua de origem por meio de guias e revistas. Portanto, passa a aprimorar sua anglofonia.

Ele se propõe a ajudar um funcionário do aeroporto a "conquistar" outra funcionária e, em troca, recebe refeições. Esse acerto vai gerando amizade entre Viktor e o funcionário, que depois lhe apresenta a outros, permitindo que joguem cartas 
todos juntos (cena aos 58'11"). Assim, passa a ter um relacionamento de amizade estabelecido naquele lugar que seria a sua "morada" - o terminal.

Em determinada cena, o diretor encontra uma brecha legal para permitir que Viktor ingresse nos Estados Unidos. Basta que ele diga que tem medo do seu país, e assim o governo americano poderia Ihe dar asilo. Porém, Viktor não consegue afirmar que tem medo do seu país (cena aos 46'21"), mas da sala na qual se encontra, referindo-se talvez à presença opressora do diretor da alfândega. Na sequência de diálogos, o personagem adiciona: "Minha casa. Eu não tenho medo da minha casa" (cena aos 46'51").

O protagonista também depara, em alguns momentos, com uma aeromoça, por quem desenvolve afeto, gerando nele a expectativa do reencontro. Os reencontros sinalizam o estímulo sentido por ele, inclusive, para poupar o dinheiro que vem ganhando (também com obras que começou a fazer no aeroporto) e comprar um terno novo. Existe, portanto, um romance em sua vida.

A partir de uma inspeção que é realizada no aeroporto, Viktor é requisitado para servir de tradutor a um viajante que porta remédios irregularmente. Ele acaba auxiliando na liberação desse estrangeiro (cena aos 69'10"). Seu feito se espalha entre os funcionários do aeroporto e ele se torna uma espécie de herói, recebendo reconhecimento pelos locais nos quais passa, no terminal, por parte dos que ali laboram. Uma imagem de suas mãos - impressa por uma copiadora sem querer durante o ato de ajuda prestada - é colada nas paredes dos restaurantes como forma de saudar a ajuda prestada.

A decisão do protagonista de ficar no aeroporto até ter autorização legal que permitisse sua saída tem um propósito claro: ele precisa cumprir uma promessa dada ao pai. Quando finalmente consegue sair, ele a cumpre e resolve, imediatamente, voltar para casa -seu país, cuja guerra havia findado.

\section{Uma tríade de autores do cotidiano}

A partir do filme referido, trazemos à tona três autores, de diferentes nacionalidades e formações, cujas obras permearam tempo e espaço de forma instigante e profunda. O primeiro deles é o sociólogo e filósofo austríaco Alfred Schütz, nascido em 1899 e falecido em 1959, nos Estados Unidos. Schütz contribuiu significativamente para os estudos sobre o mundo da vida cotidiana a partir da fenomenologia. Sem aprofundar-se especificamente nos termos tempo e espaço, o autor realiza ensaios de psicologia social nos quais destaca a percepção desses conceitos por meio do cotidiano daquele que é um forasteiro e daquele que retorna ao lugar. Para o autor, o lugar é, geograficamente, determinado espaço na superfície da terra (SCHÜTZ, 2003).

O segundo autor apresentado nesta seção é o advogado e geógrafo brasileiro Milton Santos (1926-2001), que desenvolveu sólida carreira, tendo sido exilado por anos, vivendo na França e no Canadá. Em 1996, ele recebeu o Prêmio Vautrin Lud, considerado o principal reconhecimento mundial na área de geografia. Santos (2008) observou, em sua obra, a fluidez do tempo e a globalização do espaço enquanto metáfora.

Para finalizar a tríade de pensadores aqui proposta, trazemos Marc Augé, etnólogo e antropólogo francês nascido em 1935 cuja principal obra, Não-lugares (1994), nos remete aos conceitos que entendemos como complementares aos propostos por Schütz (2003) e Santos (2008).

\section{O forasteiro e aquele que volta ao lugar como pontos de partida}

Partindo-se do pressuposto de que a realidade é fruto de construção social, e não de condição natural, e que o indivíduo, ao agir, tem suas motivações e sofre influências do meio em que se encontra, percebemos que muitas dessas ações são 
${ }^{2}$ Entendido como uma pessoa adulta, de nossa época e civilização, que é aceita ou tolerada pelo grupo do qual se aproxima. O autor ainda apresenta, como exemplo de um típico forasteiro, o imigrante, mas deixa claro que a reflexão não se limita a ele. Dessa forma, também são mencionadas personagens mais triviais, como o postulante a um clube exclusivo, o filho de um camponês que ingressa na universidade, o habitante da cidade que se estabelece no meio rural ou mesmo o que deseja ser aceito pela família da namorada. Em todas essas circunstâncias, fica claro que o forasteiro não compartilha os mesmos pressupostos básicos do grupo no qual deseja ingressar (SCHÜTZ, 1999; 2003).

${ }^{3}$ Na sua obra, Schütz (2011) apresenta a ideia de que nossas interpretações são baseadas num estoque de experiências prévias (que ele chama de conhecimento disponível) que serviriam como espécie de referencial. Esse esquema de referências, embora possa mudar e ser questionado, seria tido como certo. Assim, mesmo as experiências anteriores não questionadas "são tidas como típicas, isto é, carregam horizontes abertos de experiências antecipadas similares" (SCHÜTZ, 2011: 5).

${ }^{4}$ Assim, "el forastero, en razón de su crisis personal, no comparte los supuestos básicos mencionados; pasa a ser, esencialmente, el hombre que debe cuestionar casi todo lo que parece incuestionable a los miembros del grupo al que se incorpora" (SCHÜTZ, 1999: 100). quase automáticas, produzidas como tendência natural. Assim, trazemos à tona duas condições humanas que Schütz (2003) desenvolve sobre o homem em seu cotidiano e que nos ajudam a entender a relação do ser humano com o tempo e o espaço: o forasteiro e aquele que volta ao seu lugar.

No texto El forastero, Schütz $(1999 ; 2003)$ apresenta uma reflexão sobre a figura do forasteiro, ${ }^{2}$ analisando sua situação enquanto busca interpretar e se orientar dentro de um novo sistema cultural, de um grupo no qual esteja se inserindo. Assim, o autor questiona o comportamento e as atitudes desse recém-chegado.

Sugere que pensemos na pauta cultural da vida do grupo social, compreendida pelos valores, instituições e sistemas de orientação que caracterizam esse grupo -como usos e costumes, leis, hábitos e moda. Acredita que todo membro nascido e educado dentro de determinado grupo aceita o "esquema"3 que lhe é oferecido, razão pela qual, diante de nova pauta cultural, se vê diante da crise. ${ }^{4}$ Isso ocorre porque o forasteiro interpreta seu novo ambiente social a partir de seu pensar habitual, que é diferente do contrato cultural do novo grupo.

Com o tempo, o forasteiro vai deixando de ser observador passivo e passa a ser aspirante a membro do grupo. Aos poucos, ele começa a interpretar de forma diferente. O que inicialmente era um esquema vazio começa a ser ocupado por experiências concretas vividas. O quadro sobre o novo grupo que havia sido projetado enquanto pertencente ao seu grupo de origem principia a se mostrar inadequado. Isso fica claro no filme em análise, na medida em que o personagem Viktor Navorski começa a desvendar os detalhes do terminal, descobrindo como ganhar dinheiro e melhorar sua comunicação aprendendo a língua, fazendo amigos e até criando afeto por uma mulher. Ou seja, ele consegue atingir seus pequenos objetivos diários como comer e se relacionar - a partir do momento em que consegue interpretar como a realidade se dá naquele ambiente.

Schütz (2003) reflete também sobre aquele que volta ao seu lugar de origem. Ele apresenta essa questão como algo que nos parece ainda mais complexo do que o forasteiro que conhece o lugar pela primeira vez. Para aquele que volta, é pressuposto que esteja voltando para um ambiente conhecido e com o qual acredita ter um relacionamento íntimo (SCHÜTZ, 2003). Assim, "o forasteiro que se aproxima do grupo deve antecipar, de maneira mais ou menos vazia, o que encontrará; ao que volta ao lugar basta recorrer às suas lembranças" (SCHÜTZ, 2003: 108).

De acordo com o sociólogo, o local de um homem é o lugar ao qual ele se propõe a regressar quando está longe. O autor diferencia esse lugar de qualquer outra área geográfica localizada na terra. Para Schütz (2003), o lugar no qual me encontro é minha morada; o lugar no qual penso em permanecer é minha residência. Já o lugar do qual venho e para o qual quero voltar é o "meu lugar". Não se trata apenas de um local familiar - minha casa, minha habitação, meu jardim, minha cidade; conforme o autor, é tudo que isso representa. O caráter simbólico dessa noção, para ele, é emocionalmente evocativo e difícil de descrever. Essa ideia fica clara no episódio do filme em que o personagem deveria declarar medo de sua terra natal e, em vez disso, repete que não tem medo de sua casa, ambiente para o qual deseja voltar.

\section{Daquele que regressa ao viajante solitário}

Ao forasteiro e ao que retorna para seu lugar, contrapomos o conceito de viajante solitário desenvolvido por Augé (1994). Para o autor francês, tempo e espaço nos permitem pensar sobre um lugar em que se estabeleçam vínculos ou, ao contrário, um não-lugar de passagem, transitório, em que não há qualquer relação de pertencimento. Nesse não-lugar encontramos o viajante solitário.

Para Augé (1994: 76), o lugar antropológico é o das "possibilidades dos percursos que nele se efetuam, dos discursos que nele se pronunciam e da linguagem que o caracteriza". Ou seja, é similar ao "meu lugar" para aquele que retorna, ou do lugar de origem para aquele que é forasteiro. $O$ autor também nos propõe uma diferenciação entre lugar e espaço, sendo o espaço "mais abstrato" que o lugar. 
Ao lugar referimos ao menos um acontecimento, um mito ou uma história; o espaço, em contrapartida, "se aplica indiferentemente a uma extensão, a uma distância entre duas coisas ou dois pontos" (AUGÉ, 1994: 77).

Mas aquele que regressa ao seu lugar de origem também sofre as consequências da vida que se desenvolveu no tempo e espaço daquele lugar durante sua ausência. Ele próprio, o que esteve fora, viveu experiências que o tornam diferente, novo em relação a quando deixou "seu lugar". Em sua memória, o homem que esteve longe guarda recordações e códigos de convivência do "seu lugar". Todavia, nos alerta Schütz (2003), o próprio lugar também mudou. O exemplo que o autor aborda é o do soldado de guerra que retorna ao lar depois de um período no combate. Assim,

Quando o soldado regressa e começa a falar, se o faz, se desconcerta ao comprovar que seus ouvintes, ainda que simpatizem com ele, não compreendem a singularidade dessas experiências individuais, que o converteram em outro homem. (SCHÜTZ, 2003: 115)

Schütz (2003) observa que há discrepância entre as experiências que aquele que retorna vivenciou e a forma como os habitantes do lugar enxergam tais experiências e seu retorno. Essa diferença de significados é o maior obstáculo para o restabelecimento das relações interrompidas.

Se aquele que retorna tendo vivido nova experiência já não encontra "seu lugar" da mesma forma e tampouco é visto como "o mesmo", o que dizer do viajante solitário que circula em não-lugares?

Para Augé (1994: 73) "se um lugar pode se definir como identitário, relacional e histórico, um espaço que não pode se definir nem como identitário, nem como relacional, nem como histórico definirá um não-lugar". Segundo o autor, a supermodernidade é produtora desses não-lugares: são salas de embarques dos aeroportos, hipermercados, autoestradas. Lugares de passagem nos quais o homem não precisa se relacionar, apenas apresentar códigos, identificações, cartões de crédito. A linguagem é prioritariamente o texto: vire à direita, siga por aqui, identifique-se. São instruções, informações em que o diálogo não se faz necessário. Essa definição aparece em toda a ambientação do filme $O$ terminal, na qual o personagem Viktor continuamente cruza com pessoas em trânsito, com pressa, em um breve lapso de tempo, aguardando um voo. Da mesma forma, essa evidência fica clara na personagem da aeromoça, que afirma estar sempre "de partida", dadas as atribuições de sua função.

Para Augé (1994), o não-lugar cria uma tensão solitária. Essa tensão, segundo o autor, é vivida inclusive pelo viajante de férias. Assim,

O espaço como prática dos lugares e não do lugar procede, na verdade, de um duplo deslocamento: do viajante, é claro, mas também, paralelamente, das paisagens, das quais ele nunca tem senão visões parciais, instantâneos, somados confusamente em sua memória, e, literalmente, recompostos no relato que ele faz delas ou no encadeamento dos slides com os quais, na volta, ele impõe o comentário a seu círculo. A viagem [...] constrói uma relação fictícia entre olhar e paisagem. $E$, se chamarmos de "espaço" à prática dos lugares que define especificamente a viagem, ainda é preciso acrescentar que existem espaços onde o indivíduo se experimenta como expectador, sem que a natureza do espetáculo Ihe importe realmente. (AUGÉ, 1994: 80)

Na cena (aos 13'42") em que Viktor se vê observando a multidão, vislumbramos uma similaridade com os lugares de passagem mencionados. Para o autor francês, "certos lugares só existem pelas palavras que os evocam, não-lugares nesse sentido ou, antes, lugares imaginários, utopias banais, clichês" (AUGÉ, 1994: 88). São os lugares do cotidiano do homem moderno, que está sempre em deslocamento, 
lutando contra o tempo e o espaço. O autor observa ainda que, como os nãolugares costumam ser percorridos, eles se medem em unidades de tempo. Assim,

Os itinerários não funcionam sem horários, sem quadros de chegada ou de partida, que sempre concedem um lugar à menção dos atrasos eventuais. Eles se vivem no presente. Presente do percurso, que se materializa, hoje, nos voos de longo curso, numa tela onde se inscreve a todo instante a progressão do aparelho. Em caso de necessidade, o comandante de bordo o explicita de maneira meio redundante: "À direita do aparelho, vocês podem ver a cidade de Lisboa". Não se enxerga nada, na verdade: o espetáculo, mais uma vez, não passa de uma ideia, de uma palavra. (AUGÉ, 1994: 95)

Dessa forma, nos sugere Augé (1994), o não-lugar acaba por criar não mais uma identidade, mas uma identidade partilhada entre passageiros, clientela. Para o autor, "o espaço do não-lugar não cria nem identidade singular nem relação, mas sim solidão e similitude" (AUGÉ, 1994: 95).

\section{Da aceleração do tempo e da globalização do espaço}

Para o geógrafo brasileiro Milton Santos (2008), é a aceleração contemporânea que impõe novos ritmos ao deslocamento dos corpos e ao transporte das ideias. Ele observa que vivemos a época dos signos e que estes confundem o homem porque tomam o lugar das coisas verdadeiras. Nesse contexto, nossa primeira tentação é nos tornarmos adoradores da velocidade (SANTOS, 2008). Entretanto, essa aceleração também nos dá a sensação permanente de um "presente que foge", gera a banalização da invenção, a partir das acelerações superpostas e concomitantes.

Daí depreendemos que, se vivemos com base nas pautas culturais conhecidas, como comportar-se diante do desconhecido que se sobrepõe, daquilo que se altera rapidamente, da velocidade acelerada do tempo/espaço? Se ao forasteiro cabia entender o mundo no qual ele desejava se inserir, o que dizer do viajante solitário, se não admitir sua aparente incapacidade de criar vínculos, uma vez que sua realidade é estar sempre de passagem, assumindo uma identidade que será permanentemente momentânea?

Essas indagações nos levam novamente ao protagonista do filme, que durante os primeiros minutos da produção se encontra "absolutamente perdido" diante da realidade que se apresenta. Viktor não pode sair do aeroporto e, portanto, está impedido de cumprir o que veio fazer nos Estados Unidos; não pode retornar ao seu país, que está com as fronteiras fechadas; não compreende o inglês, língua da maioria das pessoas naquele aeroporto; e não consegue estabelecer relações imediatas, já que todos parecem estar de passagem e com muita pressa. Em determinada cena, o diretor da alfândega pronuncia: "no momento, você não é cidadão de lugar nenhum" (cena aos 6'54"). Analisando essa frase, percebemos a relevância da expressão "no momento" em nossa análise, já que ela define determinado período efêmero, da mesma forma que "Iugar nenhum" parece expressar a ausência de origem, ao mesmo tempo em que reforça como o terminal se configura em não-lugar, ou simplesmente lugar de passagem.

Schütz (2003: 110) alerta que o "lugar significa uma coisa para quem nunca o abandonou, outra para quem mora longe dele, e outra para aquele que retorna". Os não-lugares, segundo Augé (1994), resultam em viajantes solitários, homens sem identidade, com relações efêmeras, nas quais a interação se dá por textos que servem a todos os que por ali passam. Na visão de Santos (2008), a realidade atual resulta em um "tempo despótico", de poder isolado, arbitrário. "Há um relógio mundial, fruto do progresso técnico, mas o Tempo-Mundo é abstrato, exceto em relação" (SANTOS, 2008: 31). A relação pode ser entendida como o que o autor chama de "tempo do cotidiano compartilhado", "tempo plural", "o tempo dentro do tempo". Entendemos que, para Schütz (2003), trata-se da relação face a face, aquelas que 
são efetivamente compartilhadas no tempo e no espaço, independentemente do grau de intimidade que estabeleçam.

Para Santos (2008: 32), o espaço pode ser visto por meio da tecnoesfera e da psicoesfera: "A tecnoesfera é o resultado da crescente artificialização do meio ambiente. A esfera natural é crescentemente substituída por uma esfera técnica, na cidade e no campo". Observamos aqui uma grande similaridade com o não-lugar, o lugar de passagem, a paisagem vista em fragmentos, proposta por Augé (1994). A psicoesfera, por outro lado, diz respeito às crenças, desejos, vontades e hábitos, "que inspiram comportamentos filosóficos e práticos, as relações interpessoais e a comunhão com o Universo" (SANTOS, 2008: 32). A psicoesfera, do nosso ponto de vista, se relaciona ao lugar de Schütz (2003), o lugar do qual o homem saiu e deseja voltar. "O espaço se globaliza, mas não é mundial como um todo, senão como metáfora [...], quem se globaliza, mesmo, são os homens e os lugares" (SANTOS, 2008: 31).

Santos (2008) também estabelece um confronto entre o global e o lugar. O global, como o não-lugar de Augé (1994), é mediatizado. Segundo o primeiro, lugar da falsidade e do engodo: "Se o lugar nos engana, é por conta do mundo. Nestas condições, o que globaliza separa; é o local que permite a união" (SANTOS, 2008: 36). Para ele, a dimensão fragmentada é a tribo, ou a união de homens pelas suas semelhanças. Assim, "é pelo lugar que revemos o Mundo e ajustamos nossa interpretação, pois, nele, o recôndito, o permanente, o real triunfam, afinal, sobre o movimento, o passageiro, o imposto de fora" (SANTOS, 2008: 37).

Voltando à obra filmica, relembramos as amizades que Viktor constitui no aeroporto, em sua maioria funcionários de nacionalidades diferentes da estadunidense - um latino-americano e um indiano. Naquele momento e local, esses forasteiros formaram uma espécie de "tribo", cuja união se dá justamente por suas semelhanças.

\section{Considerações provisórias}

O terminal representa, em nosso sentir, algumas ideias que são apresentadas pela tríade de autores. A começar pelo forasteiro definido por Schütz (2003), que se confunde com o personagem de Viktor. Trata-se de alguém que precisa desvendar novos códigos, assumir sua condição de pessoa que não é do local, até que consiga estabelecer conexões com o lugar, que o farão compreender, em partes, seu ambiente. Entretanto, o filme se passa em um não-lugar, conforme nos define Augé (1994). Dessa forma, o forasteiro está também procurando relações em um lugar caracterizado pelo não vínculo, o não estabelecimento de contato, a simples passagem. Essa relação pode ser ainda mais complexa se acionarmos os conceitos de tempo e espaço trazidos por Santos (2008), que se configuram como aceleração e volatilidade.

Com base nos estudos de Schütz (2003), Santos (2008) e Augé (1994), podemos admitir que tempo e espaço são dimensões de singular importância no cotidiano dos homens. O espaço, que ora é lugar para o qual se volta, ora é não-lugar de passagem, ganha na contemporaneidade o status de global, embora saibamos que, na maior parte das vezes, o global é apenas um recorte da paisagem, e não um lugar de relação e construção de identidade.

O tempo, que parece acelerar no cotidiano do presente, torna-se ainda mais complexo quando se transforma na medida de deslocamento pelo espaço, sendo cada vez menor e, simultaneamente, mais abstrato. A percepção de sua irreversibilidade, à qual Schütz (2003) nos alerta quando narra as dores daquele que regressa ao seu lugar, parece ser a grande questão colocada.

Estaria a angústia atual em relação à aceleração do tempo presente justamente no fato irrefutável de sua irreversibilidade? Se o tempo não volta e o lugar se transforma mais rapidamente do que nunca, seremos todos forasteiros de nós mesmos, dos lugares que só guardamos em nossa memória? 
Para compreender esse cotidiano do mundo que não para, Augé (1994), Santos (2008) e Schütz (2003) nos trazem conceitos e abordagens que, imbricadas, nos ajudam a desvelar em partes as angústias de tempo/espaço que permeiam a humanidade de forma cada vez mais intensa. O filme O terminal, por sua vez, ilustra em alguma medida as angústias do homem que se vê preso em determinado tempo e espaço, num lugar que não é seu, tentando interpretar estruturas culturais que desconhece. Mesmo nas situações mais absurdas, como no caso do forasteiro impedido de ir adiante e de regressar, aparentemente preso numa brecha de "tempo-espaço", percebe-se o transcorrer da vida. Para muito além da dimensão de tempo e espaço, nos parece, estará o homem tratando de escrever sua história.

\section{Referências}

AUGÉ, M. Não-lugares: introdução a uma antropologia da supermodernidade. Campinas: Papirus, 1994.

FRANCE PRESSE. Personagem que inspirou "O Terminal" espera seu próprio final feliz. Folha de S. Paulo, Paris. 15 set. 2004. Disponível em: <https://bit.ly/2HPaelt>. Acesso em: 20 dez. 2017.

LOPES, P. Conheça Sir Alfred Mehran, o homem que morou 18 anos em um aeroporto. Observatório de Relações Internacionais, Ouro Preto, 25 nov. 2010. Disponível em: <https://bit.ly/2rkO5Ra>. Acesso em: 20 dez. 2017.

O TERMINAL. Direção: Steven Spielberg. Produção: Steven Spielberg, Walter F. Parkes e Laurie MacDonald. Universal City: DreamWorks, 2004. 1 DVD (128 min), color.

SANTOS, M. Técnica, espaço, tempo: globalização e meio-técnico científico informacional. 5. ed. São Paulo: Edusp, 2008.

SCHÜTZ, A. El forastero: ensayo de psicología social. In: Estudios sobre teoría social: escritos II. Trad. Nestro Miguez. Buenos Aires: Amorrortu, 1999. p. 95-107.

. Estudios sobre teoría social: escritos II. Trad. Nestro Miguez. Buenos Aires: Amorrortu, 2003.

Senso-comum e a interpretação científica da ação humana. Tradução Christina W. Andrews. Conhecendo as Ciências Sociais, Guarulhos, jul. 2011. Disponível em: <https://bit.ly/2rlj1Rm>. Acesso em: 22 dez. 2017. 